\title{
A alfabetização \\ no contexto de uma formação humana
}

\author{
Literacy in the process \\ of human formation
}

\section{La alfabetización en el contexto}

de una formación humana

LETÍCIA ARRUDA*

Universidade do Planalto Catarinense, Lages-SC, Brasil.

MARIA SELMA GROSCH**

Universidade do Planalto Catarinense, Lages-SC, Brasil.

VANICE DOS SANTOS $* * *$

Universidade do Planalto Catarinense, Lages-SC, Brasil.

CARMEN LUCIA FORNARI DIEZ $Z^{* * * *}$

Universidade do Planalto Catarinense, Lages-SC, Brasil.

\begin{abstract}
RESUMO: O texto apresenta uma reflexão sobre a educação escolar, com destaque para a importância da alfabetização no desenvolvimento dos seres em formação articulada com algumas relações e representações do fazer humano. Para a discussão, foram utilizadas
\end{abstract}

* Pedagogia pelo Centro Universitário FACVEST, é mestranda em Educação pela Universidade do Planalto Catarinense. Atua na Rede Municipal de Educação de Lages e integra o grupo de pesquisa NUPEB. E-mail: $<$ letiarruda2908@gmail.com>.

* Doutora em Educação pela Universidade Federal de Santa Catarina e Pós-Doutoranda no Programa de Pós-Graduação em Educação da UNOESC. É Professora aposentada da Universidade Regional de Blumenau. Atualmente é professora titular no PPGE- Programa de Pós Graduação em Educação da Universidade do Planalto Catarinense em Lages. E-mail: <selmagrosch@gmail.com>.

*** Doutora em Educação pela Universidade Federal do Rio Grande do Sul e Mestre em Filosofia pela Universidade do Vale do Rio dos Sinos, é Docente pesquisadora no Programa de Pós-Graduação em Educação da Universidade do Planalto Catarinense. E-mail: <profa.vanice@uniplaclages.edu.br>.

****Pós-doutora em Filosofia pela Universidade Carlos III de Madrid. Possui mestrado em Educação pela Universidade Federal do Paraná e doutorado em Educação pela Universidade Metodista de Piracicaba. É aposentada como professora associada da Universidade Federal do Paraná. Atualmente é professora do mestrado em Educação da Universidade do Planalto Catarinense. E-mail:<miuxe@uniplaclages.edu.br>. 
as contribuições de diferentes autoras/es que tratam da formação humana integral, alfabetização e formação de professoras/es, pois, trata-se de um processo que necessita do protagonismo e do trabalho conjunto de todos os envolvidos no seu desenvolvimento.

Palavras-chave: Alfabetização. Educação. Formação humana. Formação de professoras/es.

\begin{abstract}
The text presents a reflection on school education, highlighting the importance of literacy in the development of beings in articulated formation with some relationships and representations of human production activities. For the discussion, the contributions of different authors that deal with integral human education, literacy and teacher training were used, because it is a process that requires the protagonism and the joint work of all those involved in its development.
\end{abstract}

Keywords: Literacy. Education. Human formation. Teacher training.

RESUMEN: El texto presenta una reflexión sobre la educación escolar, con destaque para la importancia de la alfabetización en el desarrollo de los seres en formación articulada con algunas relaciones y representaciones del hacer humano. Para la discusión, se utilizaron las contribuciones de diferentes autoras/es que tratan de la formación humana integral, alfabetización y formación de profesoras/es, pues se trata de un proceso que necesita del protagonismo y del trabajo conjunto de todos los involucrados en su ejecución.

Palabras clave: Alfabetización. Educación. Formación humana. Formación de profesoras/es.

\title{
Introdução
}

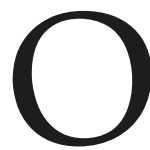

artigo tem o intuito de aprofundar alguns estudos sobre formação do ser humano e a atual conjuntura educacional, enfatizand o a primazia do processo de alfabetização, que possibilita às/aos professoras/es oportunizar aos estudantes condições de independência no acesso aos conhecimentos já disseminados, pois a alfabetização é a iniciação do estudante no mundo letrado. Cabe destacar que em uma sociedade letrada, a alfabetização é uma das etapas que irá lhe proporcionar transformações de sua realidade e capacidade de edificação de novos e diferenciados conhecimentos, 
aliados ao seu cotidiano. Sendo assim, é necessário observar as diferentes perspectivas que norteiam a ação pedagógica, bem como alguns dos aspectos que já foram analisados por estudiosos. Dessa forma, apresentamos a necessidade de um início de escolarização bem fundamentado e com objetivos claros na formação dos estudantes. Essa análise teve como base os estudos de Comênio (1957), Rousseau (1995), Jaeger (2001), Kant (2012), Dussel (2017), com aspectos pertinentes à formação do ser humano e sua educação primária, bem como as contribuições de Soares (2017), Scheibe (2008), Grosch (2018), Gatti (2011), Freire e Macedo (2015), entre outros, com aspectos relacionados à alfabetização e formação de professoras/es. E ainda, procedemos à consulta de encaminhamentos nacionais da educação e resultados de avaliações, tendo como pressuposto a necessidade de um processo de alfabetização que gere possibilidades de desenvolvimento.

Trabalhar com educação exige uma análise profunda das diversas questões que englobam tanto a parte prática do fazer pedagógico, como as estruturas teóricas que permeiam todas as relações envolvidas no espaço escolar, considerando a estreita relação teoria-prática. O tema alfabetização é de grande pertinência, pois a partir dele é possível adentrar em outras questões e promover maior autonomia aos estudantes. Porém, ele não é um movimento solitário, exige variadas relações e, principalmente, um conhecimento maior da educação e dos envolvidos no processo, sem desconsiderar a formação do ser social, que juntamente com a alfabetização se constitui nas relações sociais.

A educação passa atualmente por muitas dificuldades, decorrentes de mudanças tecnológicas e sociais, o que exigiu e exige constantes alterações de uma instituição que por vezes insiste em manter bases tradicionais e supostamente inquestionáveis. Estudiosos de séculos passados já demonstravam preocupação com o papel da instituição escolar, desde quando se começou a analisar os diferentes aspectos que englobam o desenvolvimento de um ser humano, e a escola necessita considerá-los de modo a atualizar suas práticas cotidianas, dadas as mudanças socio-históricas.

Comênio (1957) defendia a educação necessária aos seres para o tornar-se homem. Rousseau (1995) já alertava para a observação com os primeiros cuidados de uma criança, com a formação de um sujeito melhor e mais apto a relacionar-se com a natureza e outros seres, mantendo um equilíbrio entre os diferentes saberes e respeitando-os como seres em formação e não cópias em miniatura dos adultos. Kant (2012) demonstrou a importância da educação na formação do ser humano e também a significância do adulto perante essa formação, com condução e trabalho conjunto em busca de uma educação mais abrangente e transformadora. Jaeger (2001) realizou reflexões sobre a Paideia na educação do homem grego e sua extrema preocupação com a formação, além da construção de bases que norteiam a visão que temos do fazer educacional até os dias de hoje.

Analisando esses e outros estudos, verifica-se a necessidade de um embasamento teórico que possa ocasionar entendimento e mudanças significativas, além das relações possíveis para aprimorar o fazer pedagógico e auxiliar o desenvolvimento humano, 
proporcionando uma alfabetização adequada e condizente com as necessidades contemporâneas. As crianças precisam ser levadas a descobrir o mundo e não somente ser inseridas nele, eé papel das/os professoras/es que convivem com elas encaminhá-las nas descobertas necessárias e motivá-las para a construção de novas teias de relações e aprendizados. Alfabetizar uma criança é lhe dar a possibilidade de (re) conhecer o mundo com seus próprios olhos, além de oportunizar os caminhos que queiram trilhar, com uma formação sólida e capaz de promover mudanças se assim for necessário, com respeito ao outro e à dignidade humana.

\section{Relacionando conhecimentos}

Desde os tempos remotos, estudiosos realizam indagações e reflexões acerca do processo educacional. Kant nos alertou que: "O homem é a única criatura que tem de ser educada" (KANT, 2012:9). Essa educação engloba uma série de cuidados que a princípio são realizados por outra pessoa, diferentemente dos animais que no início de sua vida são auxiliados para alimentar-se, porém já realizam tarefas necessárias à sua existência de maneira independente. A palavra cuidados refere-se à precaução necessária para que novos seres humanos não utilizem suas capacidades inadequadamente.

Por meio da disciplina, o homem vai aprendendo a utilizar suas forças de modo a desenvolver habilidades para suprir suas necessidades, construindo sua razão e maneiras de agir, controlando seus impulsos, se diferenciando assim dos animais. Além disso, vai se preparando para viver e seguir regras da sociedade e não somente satisfazendo suas vontades, bem como passa a ir se acostumando a usufruir da razão. O homem por si só, carrega um espírito de liberdade que necessita ser controlado pelos cuidados e formação, com disciplina e instrução (KANT, 2012).

Sua formação acontece pela educação mediante o repasse de outros já educados e vai se aprimorando, sendo possível o avanço da humanidade e um conhecimento mais abrangente e transformador. É nesse ponto que ressaltamos o papel das/os professoras/es, mesmo que o processo na maioria das vezes se inicie no âmbito familiar, dando continuidade no espaço escolar, que é o local - da educação formal - em que ocorre o processo de consolidação, aprendizado e construção de novos e variados conhecimentos. Essa edificação de saberes ocorre mediante a aquisição de habilidades e relações com o outro, que começa na educação infantil e continua nas séries seguintes através do processo de alfabetização, que permite ao estudante acessar o mundo letrado e lhe proporciona condições de autonomia na busca pelo conhecimento. Como afirmava Kant (2012), na aquisição de autonomia que gera nos seres a educação, é necessário um olhar atento e minucioso, pautado na experiência das/os professoras/es para oportunizar aos 
estudantes condições de desenvolvimento, pois o fracasso desse momento pode gerar consequências nocivas e muitas vezes irreversíveis.

É papel da escola, desde os primeiros anos, promover situações em que as crianças explicitem de forma oral ou por meio de registros as visões do mundo. Muitos pensam que a alfabetização é somente a transcrição de códigos da norma culta, porém muito mais que isso é a aquisição, pela criança, de maneiras de demonstrar a realidade que a cerca, além de proporcionar condições para atingir níveis mais elevados do conhecimento, podendo vir a modificar a realidade em que vive. Assim como o conceito de educação sofreu algumas mudanças ao longo dos anos, "também o de alfabetização tem sofrido transformações ao longo dos tempos" seja no entendimento ou nas práticas que "articulam e refletem as complexas relações entre educação e sociedade" (PÉREZ, 2008:178).

Na Grécia e Roma Antiga os ensinamentos eram repassados de maneira oral e a escrita pouco contemplada; posteriormente, a escrita ficou restrita à Igreja, que instituiu a leitura silenciosa. Com a criação da imprensa, a Igreja perde o monopólio intelectual, o livro se torna algo com valor econômico, porém a ênfase ainda permanece na leitura, que constituía a alfabetização da época e era de incumbência da família e da Igreja. Desse modo, a Igreja controlava os conhecimentos acessíveis aos estudantes. No Brasil, também, o ensino ficava à cargo das instituições religiosas e não era acessível para todos; e, com a expulsão dos jesuítas em 1759, foi instituído o ensino laico e público, sem grandes mudanças. Já no século XIX, com a chegada da Família Real, algumas medidas foram tomadas em relação à educação, que não era o foco principal. Somente no início do século XX é que surgem as primeiras universidades no Brasil e o sistema educacional passa por várias reformas ao longo dos anos. O maior destaque na educação brasileira ocorre com a promulgação da Constituição Federal de 1988, que já instituía em seu Art. 214 "a erradicação do analfabetismo", além da "melhoria da qualidade do ensino", questões estritamente relacionadas à alfabetização.

Mais tarde, novamente aparecem essas determinações no Plano Nacional de Educação, com a meta 5, de "alfabetizar todas as crianças, no máximo, até o final do 3ํo (terceiro) ano do ensino fundamental", meta 7 "fomentar a qualidade da educação básica em todas as etapas e modalidades [...]", meta 9 "elevar a taxa de alfabetização da população com 15 (quinze) anos ou mais [...] erradicar o analfabetismo absoluto e reduzir em $50 \%$ (cinquenta por cento) a taxa de analfabetismo funcional"; mas, mesmo com todas tentativas para zerar essas taxas, temos um contingente enorme no Brasil de pessoas analfabetas, de acordo com Pesquisa Nacional do IBGE por Amostra de Domicílios Contínua (Pnad Contínua) de 2017, ainda são 11,5 milhões de habitantes brasileiros que não tiveram acesso à alfabetização, em sua maioria idosos, que foram privados da educação escolar. Porém, há também aqueles que frequentaram a escola e não atingiram níveis mais elevados de alfabetização, ou seja, tiveram acesso à educação escolar, mas possuem resquícios de processos falhos e que deixaram lacunas, de acordo com o Indicador de Alfabetismo Funcional (Inaf) 
2018, três em cada dez brasileiros entre 15 e 64 anos fazem parte desse grupo, que foi de certa forma preterido das práticas educacionais que dão condição de enfrentamento de diferentes situações, "Daí a responsabilidade da escola, especialmente da escola pública, de oferecer oportunidades de alfabetização e letramento a todos" (CARVALHO, 2011:16).

Deste modo, proporcionar condições de alfabetização na idade correta é uma das maneiras de solucionar problemas de repetência e evasão escolar, já que muitos dos alunos que passam por essas duas situações da educação foram de certa maneira excluídos do processo de alfabetização e letramento. Alfabetizar, como defende Soares (2017), é um processo complexo e que exige que as/os professoras/es o compreendam. É fundamental a aprendizagem inicial da língua escrita, bem como a valorização e olhar atento para os profissionais que trabalham com essas séries de iniciação escolar. Para tanto, se faz necessário que a formação continuada oportunize às/aos professoras/es condições de auxílio e busca por soluções aos fazeres inerentes às classes de alfabetização, ou seja, as/os professoras/es necessitam participar de uma formação que privilegie encaminhamentos referentes a essa fase do estudante.

É importante ressaltar que a educação é um bem comunitário “[...] não é uma propriedade individual, mas pertence por essência à comunidade" (JAEGER, 2001:4), resultado do entendimento da cultura que orienta os seres humanos e seus grupos, pois é algo ativo no cotidiano e evolução da sociedade. Sua história está ligada às mudanças de padrões, que quando desestabilizados prejudicam a ação de educar. "Uma educação consciente pode até mudar a natureza física do Homem e suas qualidades, elevando-lhe a capacidade a um nível superior" (JAEGER, 2001:3). A educação serve como meio de transmissão das especificidades e culturas de um povo às suas futuras gerações, e isso é realizado por meio de conhecimentos adquiridos, sendo que uma educação consciente consegue elevar as capacidades humanas relacionando todos os aspectos envolvidos no ser.

Os gregos já se preocuparam séculos atrás, e se acredita ser hoje a grande questão da educação, com a formação integral do ser, pautada em conhecimentos que permitam ao estudante desenvolver suas diferentes habilidades, preparando-o para ter possibilidades de relacionar em suas vivências o maior número de diversidades possíveis. Assim, é imprescindível que a escola oportunize condições para que estudantes associem teoria e prática, conceitos e saberes cotidianos. Não podemos esperar que outra instituição o faça, o mundo fora dos muros da escola exige capacidades e habilidades antes ignoradas, sendo que para isso é necessário encaminhamento e trabalho conjunto, além de um aperfeiçoamento constante que permita às/aos educadoras/es possibilidades de acesso ao nível e exigência dos estudantes, frente às mudanças tecnológicas e sociais.

A educação participa na vida e no crescimento da sociedade, tanto no seu destino exterior como na sua estruturação interna e desenvolvimento espiritual; $\mathrm{e}$, uma vez que o desenvolvimento social depende da consciência dos valores que regem a vida humana, a história da educação está essencialmente condicionada pela transformação dos valores válidos para cada sociedade (JAEGER, 2001:4). 
Para tanto, é primordial que as/os professoras/es tenham acesso a uma formação que lhes oportunize condições de adequação às necessidades educacionais que irão enfrentar. Os cursos de formação inicial de professoras/es passam por sérios problemas, não possibilitando o total preparo das/os profissionais nem em aspectos práticos e nem teóricos. Novos formatos de licenciaturas surgiram para abarcar as necessidades de mercado, porém aspectos essenciais foram deixados de lado, e fatores primordiais à função de ser professora/or vão sendo generalizados: “[...] o professor continua sendo alguém tratado de modo genérico e abstrato, não se levando em conta as circunstâncias reais que delimitam sua esfera de vida e profissão" (GATTI, 2011:153).

Ainda na mesma ideia, Imbernón (2011) retrata que:

\begin{abstract}
Há muito tempo, a formação inicial dos professores é fraca. Ela denota grande despreocupação e falta de vontade por parte das administrações públicas em assumir a profissão e encarar o fato de que ela envolve valores morais e éticos e trabalha com alunos que vivem situações problemáticas diversas. Em um cenário ideal, o curso superior deveria girar sobre o eixo da relação entre teoria e prática educacional, além de oferecer uma visão holística e crítica das disciplinas - sejam de conteúdo científico ou psicopedagógico (IMBERNÓN, 2011).
\end{abstract}

É urgente a necessidade de mudanças, de modo que o ensino superior venha a contribuir de maneira efetiva e constante com a função social da qual é agente fundamental. "Talvez melhores respostas para o ensino, e portanto para a formação do professor, sejam encontrados a partir de enfoques de natureza mais pedagógica e menos psicológica, mais relacional e menos individual" (GATTI, 2011:157). Antes de mais nada, é necessário ter em mente a real função da escola, para que questões cotidianas e essenciais ao ato de ensinar sejam pauta também da formação de formadoras/es.

Continuamente são criados diferentes programas no intuito de suprir as carências de uma formação inicial deficitária e pouco contundente. As propostas vêm de diferentes entidades e com propósitos claros na melhoria da qualidade na educação, porém “Qualquer programa que tenha como foco a erradicação definitiva do analfabetismo do País deve priorizar um elemento que é central para o seu sucesso: a qualificação dos alfabetizadores" (INEP, 2003:11).

De acordo com Gatti (2011) nas últimas décadas, houve um crescimento na defesa de formação continuada, ocasionado pelas necessidades do mercado de trabalho e também pela constatação mediante avaliação da defasagem dos estudantes. Relacionado a isso, visualizamos uma mudança na maneira como se vê o processo de alfabetização, pois, até meados dos anos 60, o estudo era baseado em questões de como se ensina. A partir dos anos 80, o foco mudou para como se aprende. Mudando o eixo de investigação, foi possível perceber muitos fatos, nas crianças, que antes não eram analisados, como por exemplo a influência que o convívio social produz nelas, bem como a existência ou não de oportunidades de aprendizagem desde o nascimento. "A divulgação desses resultados 
de pesquisas por várias secretarias de educação desencadeou em uma parcela pequena (mas ativa e comprometida) de alfabetizadores e técnicos, um esforço de revisão das práticas de alfabetização" (PCN, BRASIL:1997).

Nesse esforço por melhores resultados, é imprescindível ainda a formação continuada que irá auxiliar e promover com as/os professoras/es oportunidades de discussão e ampliação dos saberes necessários à sua prática pedagógica cotidiana. Para Scheibe (2008), "Há necessidade de investimento massivo na formação de licenciandos, compondo licenciaturas integradas e novos desenhos curriculares, fortalecendo especialmente a formação de professores alfabetizadores" (SCHEIBE, 2008:51), haja vista que a alfabetização é a iniciação do estudante no mundo letrado, o que irá permitir transformações de sua realidade e capacidade de edificação de novos e diferenciados conhecimentos aliados ao seu cotidiano.

Nossa sociedade passa por mudanças constantes, em decorrência, o papel das/os professoras/es a cada dia se torna mais complexo e desafiador, de modo que não é mais possível uma escola que se detenha simplesmente no repasse de conteúdos, sem levar em conta os inúmeros aspectos envolvidos na relação entre escola e estudante. Nesse sentido, é necessária uma revisão de conceitos e busca por diferentes caminhos, para se alcançar o maior número possível de estudantes, bem como solucionar questões pontuais, pois,

Em um universo de pluralidades como o da escola, há busca constante de realização da pessoa e suas singularidades, ao mesmo tempo em que se estabelecem contribuições para o avanço do gênero humano. O significado e o sentido do trabalho docente estão sempre ancorados nos fins sociais mais amplos, ainda que não se tenham clareza de tais propósitos. E nesse caso, a formação continuada pode atuar como espaço de ação, intermediando a discussão dos aspectos condicionantes da atividade do professor, buscando a exploração dos limites e das possibilidades oferecidos pelas condições existentes e investindo na promoção de transformações para além das condições dadas no espaço e tempo presentes (GROSCH, 2018:73).

Podemos refletir, também com a mesma intenção de uma educação para a autonomia, sobre as contribuições de Rousseau (1995), que alertava para a condição de se fazer com que crianças pensem por conta própria a partir de uma educação libertadora e também guiada pela razão e desenvolvimento de suas potencialidades. Com uma educação voltada para si que possibilite ter e tomar posicionamentos, formar-se como homem e cidadão e capaz de enfrentar as adversidades da vida, através de suas vivências, permitindo-se transformar para mudar a lógica dos modelos impostos: "Tudo o que não temos ao nascer, e de que precisamos adultos, é nos dado pela educação" (ROUSSEAU, 1995:10).

Para Rousseau (1995), a instrução de um ser se inicia no nascimento, no contato com pessoas que lhe cuidarão é o começo da educação, as mediações do adulto perante ações dessa criança é que irão determinar o seu entendimento frente às situações. Tais considerações nos levam a pensar que esta é mais uma postura necessária às/aos professoras/es que convivem com esses seres em formação nos primeiros anos de sua vida. O início da 
escolarização não pode ser somente no sentido de agregar conteúdos do currículo, mais importante talvez seja a preparação desses estudantes para apropriar-se desses saberes. Essa preparação começa no convívio familiar, dando continuidade posteriormente na escola, que é o local onde as crianças irão se deparar com diferenças e maior número de negações, sendo necessário enfrentar as frustrações. "Assim, acostumando-se desde cedo, a subordinar seus desejos a suas forças, elas sentirão pouco a privação do que não estiver em seu poder" (ROUSSEAU, 1995:50).

É imperativo ressaltar que estimular os estudantes e lhes agregar valores é um preceito básico dos primeiros anos de escolarização e, como afirma Soares (2017), é fundamental a aprendizagem inicial da língua escrita, bem como a valorização e olhar para as/os professoras/es que trabalham com essas séries de iniciação que começam bem antes do ensino fundamental. Algo que vai ao contrário das políticas públicas que dão ênfase a melhorias e avaliações às fases finais de escolarização. Se já nos anos iniciais um estudante sente-se excluído das práticas utilizadas em sala de aula, muito dificilmente conseguirá estímulos para crescer e enfrentar suas dificuldades no espaço escolar.

A educação não pode mais ficar resguardada dentro dos muros da escola, é favorável que ela seja inconstante, mutável e se adeque aos momentos e dilemas atuais, os estudantes precisam participar ativamente desse processo e aprender por meio das vivências. Desde muito pequenas, as crianças necessitam ser estimuladas a tomar decisões, mostrar suas vontades e sentimentos, a fim de que possam saber defender suas opiniões e argumentá-las, desenvolvendo assim espíritos mais críticos e participativos. Tal exemplo fora defendido por Comênio, na Didática Magna, “[...] segue-se que instruir bem a juventude não consiste em rechear os espíritos com um amontoado de palavras, de frases, de sentenças e de opiniões tiradas de vários autores, mas em abrir-lhes a inteligência à compreensão das coisas, [...]" (COMÊNIO, 1957:256).

A partir das contribuições de Comênio (1957) se constituiu o modelo de escola que permanece até os dias atuais. O referido educador defendia a disciplina necessária ao fazer pedagógico, bem como a aplicação de um método que iria organizar o processo de aprendizagem com ensino gradual e acesso de todos ao conhecimento. Kant (2012) convergia seu pensamento com Comênio na necessidade da formação do ser para tornar-se homem, e postulava que a aprendizagem ocorria em meio a outros seres humanos. "Ninguém acredite, portanto, que o homem pode verdadeiramente ser homem, a não ser aquele que aprendeu a agir como homem, isto é, aquele que foi formado naquelas virtudes que fazem o homem" (COMÊNIO, 1957:120).

Esse processo de representação do conhecimento se torna claro, quando percebemos que habitualmente as crianças não fazem o que é solicitado, porém reproduzem comportamentos e atitudes às vezes visualizados uma única vez, o que torna os adultos que com ela convivem responsáveis por demonstrar aprendizado muito mais pela ação que somente pela oralidade. Nessa função também a escola e professoras/es necessitam 
cuidado e atenção - o exemplo de qual concepção de cidadãos queremos formar é o ponto de partida para nossas atitudes e pensamentos, pois, a maneira como nos posicionamos perante as situações irá influenciar ativamente nossas orientações. O adulto é o responsável por encaminhar os novos seres que estão em formação. Orientá-los no conhecimento e caminhos do mundo é também nossa função. “Face à criança, é como se ele fosse um representante de todos os habitantes adultos, apontando os detalhes e dizendo à criança: - Isso é o nosso mundo" (ARENDT, 1992:239).

A escola é a instituição que mais se manteve inalterada com o passar dos anos e avanços tecnológicos, sendo considerada pelo senso comum e muitas vezes por quem está inserido nesse processo como uma instituição ultrapassada; porém é também a mais cobrada no sentido de oportunizar suporte e condições de evolução dos seres. Há dificuldades históricas no Brasil em relação aos procedimentos de alfabetização que permanecem muitas vezes enraizados nos conceitos e didáticas obsoletos, o que torna o processo desconectado do contexto social e de práticas inovadoras, comprometendo a credibilidade da escola, fazendo-se necessária uma alteração na maneira com que adentram, mas, principalmente a continuidade dos estudantes no meio escolar e as oportunidades que darão suporte frente às necessidades cotidianas. Esse novo ser que chega à escola precisa ser tratado de tal maneira que possa se desenvolver e conhecer o mundo que o cerca, e não somente como reprodutor de antigas práticas e modelos.

Se a criança não fosse um recém-chegado nesse mundo humano, porém simplesmente uma criatura viva ainda não concluída, a educação seria apenas uma função da vida e não teria que consistir em nada além da preocupação para com a preservação da vida e do treinamento e na prática do viver [...] (ARENDT, 1992:235).

Os agentes da educação podem criar possibilidades para a duração da escola “[...] dotá-la de condições de certa perdurabilidade [...]” (DUSSEL, 2017:106). É necessário buscar estratégias para o futuro “[...] para atuar como espaço de iguais” (DUSSEL, 2017:107), com auxílio de todos os envolvidos no processo, para aprimorar espaço e estrutura escolar perante a realidade. Há também que se pensar na parte prática, o que e como vamos utilizar para modificar e melhorar as condições da escola, para mantê-la como um espaço de formação de seres em desenvolvimento, aptos para a vivência e convivência no mundo atual. Para tanto, a alfabetização precisa ser pensada e construída como um processo emancipatório e político que oportunize aos estudantes uma identificação e capacidade de enfrentamento, independente da classe social ou comunidade em que está presente. "Para que a ideia de alfabetização ganhe significado deve ser situada dentro de uma teoria de produção cultural e encarada como integrante do modo pelo qual as pessoas produzem, transformam e reproduzem significado" (FREIRE; MACEDO, 2015:170). A escola tem papel fundamental na construção de uma sociedade mais justa, pois, por meio da leitura e escrita há um crescimento individual e coletivo, que irá oportunizar condições 
de se atingir níveis mais elevados de conhecimento, com avanços, oportunizando aos seres humanos melhores condições sociais.

\section{Considerações finais}

O texto abordou alguns aspectos relacionados à formação do ser humano e sua educação, enfatizando a relevância da alfabetização para proporcionar mais autonomia e dignidade, a fim de promover o desenvolvimento integral do estudante. Conclui-se que precisamos analisar os diversos aspectos envolvidos e levar em consideração os saberes antes constituídos, pois mesmo que sejam de explorações e registros de outros séculos, muito auxiliam e têm uma linguagem extremamente atual e condizente, dando ênfase às descobertas e análises recentes. Cabe destacar que recorremos aqui a autores considerados clássicos da educação.

Mediante os textos consultados, podemos perceber a grande relação da filosofia com o tema da educação. Ensinamentos e métodos permanecem sendo utilizados, questionados e até remodelados. A angústia e a necessidade da pesquisa frente aos desafios na educação não são algo novo, os temas pertinentes à educação e escola inquietam e instigam a busca por mudanças há muito tempo, o que nos revela que esse movimento tem sido inerente à vida humana.

Sendo assim, é de suma relevância a temática, na medida em que proporciona ampliação de conhecimentos e relação direta com o ser/fazer pedagógico, de modo a auxiliar e possibilitar uma mudança de paradigmas, com ênfase na edificação de saberes e formação de seres mais aptos a viver em sociedade, com sua individualidade e dignidade respeitadas e valorizadas. Neste contexto, para que haja sucesso no processo de alfabetização, se faz necessário professoras/es engajadas/os, preparadas/os e motivadas/ os para exercer com maestria essa função; e da mesma forma que as políticas públicas precisam ser colocadas em prática, a educação necessita ser prioridade, pois é ela que irá desencadear mudanças em outras instâncias e proporcionar resultados mais favoráveis em todos os níveis de desenvolvimento.

A educação é um direito de todos, e a organização da escola necessita possibilitar o acesso dos estudantes, mas, principalmente, sua permanência com qualidade e avanços, algo que será mais dinâmico se todos tiverem acesso a um processo de alfabetização mais exitoso. Nas práticas alfabetizadoras, educandos e professoras/es precisam ser reconhecidas/os e solidárias/os na construção do conhecimento por meio de processos de participação democrática e dinamicidade nos processos de ensino e aprendizagem. 


\section{Referências}

ARENDT, Hannah. Entre o passado e o futuro. Trad. Mauro William Barbosa de Almeida. São Paulo: Perspectiva, 1992.

BRASIL. Constituição (1988). Constituição da República Federativa do Brasil. Brasília: Senado Federal, 1988.

BRASIL. Parâmetros Curriculares Nacionais: Língua Portuguesa. Brasília-DF: Ministério da Educação. Secretaria da Educação Fundamental, 1997.

BRASIL. Lei no $\mathbf{1 3 . 0 0 5}$, de 25 de junho de 2014. Plano Nacional de Educação 2014-2024. Brasília: Câmara dos Deputados, Edições Câmara, 2014. Disponível em: http://pne.mec.gov.br/images/pdf/ pne_conhecendo_20_metas.pdf. Acesso em: 03 ago. 2018.

CARVALHO, Marlene. Alfabetizar e letrar: um diálogo entre a teoria e a prática. Petrópolis: Vozes, 2011.

COMÊNIO, João Amós. Didáctica Magna. Trad. Joaquim Ferreira Gomes. 3aㅗ ed. Lisboa: Fundação Calouste Gulbenkian, 1957.

DUSSEL, Inés. Sobre a precariedade da escola. In: LARROSA, Jorge (Org.). Elogio da escola. Trad. Fernando Coelho. Belo Horizonte: Autêntica, 2017. p. 87-111.

FREIRE, Paulo; MACEDO, Donaldo. Alfabetização: leitura do mundo, leitura da palavra. Trad. Lólio Lourenço de Oliveira. 7. ed. Rio de Janeiro: Paz e Terra, 2015.

GATTI, Bernadete Angelina. Organização Walter E. Garcia. Bernadete A. Gatti: educadora e pesquisadora. Belo Horizonte: Autêntica, 2011.

GROSCH, Maria Selma. Ação humana, atividade docente e formação continuada de professores: perspectiva a partir do pensamento de Hannah Arendt. Revista Tempos e Espaços em Educação, São Cristóvão, UFS, v. 11, n. 25, p. 71-82, 2018.

IBGE. Pesquisa Nacional por Amostra de Domicílios Contínua 2016-2017. Disponível em: https:// biblioteca.ibge.gov.br/visualizacao/livros/liv101576_informativo.pdf. Acesso em: 22 nov. 2018.

IMBERNÓN, Francisco. Entrevista concedida a Noêmia Lopes. Gestão Escolar, 1 jul. 2011. Disponível em: gestaoescolar.org.br/conteudo/456/francisco-imbernon-fala-sobre-caminhos-para-melhorar-aformacao-continuada-de-professores. Acesso em 12 jun. 2018.

INAF. Inaf Brasil 2018: resultados preliminares. Instituto Paulo Montenegro. Disponível em: http:// acaoeducativa.org.br/wpcontent/uploads/2018/08/Inaf2018_Relat\%C3\%B3rio-ResultadosPreliminares_v08Ago2018.pdf. Acesso em 22 nov. 2018.

INEP - Instituto Nacional de Estudos e Pesquisas Educacionais Anísio Teixeira. Mapa

do Analfabetismo no Brasil. 2003. Disponível em: http://portal.inep.gov.br/ documents/186968/485745/Mapa+do+analfabetismo+no+Brasil/a53ac9ee-c0c0-4727-b216035c65c45e1b?versio. Acesso em 22 nov. 2018.

JAEGER, Werner Wilhem. Paidéia: a formação do homem grego. Trad. Artur M. Parreira. 4.ed. São Paulo: Martins Fontes, 2001.

KANT, Immanuel. Sobre a pedagogia. Trad. João Tiago Proença. Piracicaba: Editora da Unimep, 2012. 
PÉREZ, Carmen Lúcia Vidal. Alfabetização: um conceito em movimento. In: GARCIA, Regina Leite; ZACCUR, Edwirges (Orgs.). Alfabetização: reflexões sobre saberes docentes e saberes discentes. São Paulo: Cortez, 2008. p. 178-201.

ROUSSEAU, Jean Jacques. Emílio ou da educação. Trad. Sérgio Milliet. 3. ed. Rio de Janeiro: Bertrand Brasil, 1995, p. 1-57.

SCHEIBE, Leda. Formação de professores no Brasil: a herança histórica. Revista Retratos da Escola, Brasília, Esforce, vol. 02. n. 02-03, p. 41-53, jan. / dez. 2008.

SOARES, Magda. Alfabetização e letramento. 7. ed. São Paulo: Contexto, 2017. 